\title{
MONEY AND GROWTH IN A PRODUCTION ECONOMY WITH MULTIPLE ASSETS
}

\author{
LeO KaAS \\ University of Vienna
}

Gerd WeinRich

Catholic University of Milan

We consider a Diamond-type model of endogenous growth in which there are three assets: fiat money, government bonds, and equity. Because of productivity shocks, the equity return is uncertain, and risk-averse investors require a positive equity premium. Typically, there exist two steady states, but only one of them turns out to be stable. Tight monetary policy is harmful for growth in the stable steady state. These results hold under four different monetary policy strategies applied by the monetary authority. A monetary contraction increases the bond return and reduces the equity premium and thereby capital investment and growth.

Keywords: Monetary Policy, Endogenous Growth, Overlapping Generations

\section{INTRODUCTION}

This paper deals with the question of how monetary policy affects growth. The traditional literature on monetary growth theory emphasizes the Mundell-Tobin or "portfolio" effect, which says that money growth affects the capital stock positively since higher inflation reduces the return on real balances, which induces investors to reallocate savings from money to capital (see Mundell, 1965 and Tobin, 1965). Within dynamic general equilibrium models, however, such an effect is hard to find and most studies report either superneutrality of money or even a negative relation between money growth and real activity. ${ }^{1}$ Just as the theoretical literature, empirical studies on this issue also draw different conclusions. ${ }^{2}$

Most of the theoretical literature considers only a single outside asset (money) and examines the effects of variations of the growth rate of this asset. In such a framework, however, the impact of different monetary strategies on real activity cannot be studied adequately. To address this issue, Schreft and Smith (1997, 1998)

The research on this paper originated while Gerd Weinrich was visiting the Institute of Advanced Studies, Vienna. The authors thank an anonymous associate editor, Klaus Ritzberger, participants at the EEA2000 Congress, and seminar participants at the Catholic University of Milan for helpful comments. All remaining errors and shortcomings are our own responsibility. Address correspondence to: Leo Kass, Department of Economics, University of Vienna, Hohenstaufengasse 9, 1010 Vienna, Austria; e-mail: leo.kaas@univie.ac.at. 
consider a Diamond-type overlapping generations model with outside money and government bonds in which different monetary policy strategies such as a constant money growth rule or an inflation-targeting or interest-targeting rule can be studied. They show that there exist multiple steady states and that the effects of monetary policy on the output level in these steady states are ambiguous.

Schreft and Smith assume that government bonds and physical capital are perfect substitutes in the portfolios of consumers and that firms finance their capital investments by loans for which they pay the same interest rate as the government on Treasury bills. Thus, the rates of return on government bonds and capital coincide, and monetary policy affects both interest rates in the same way. For instance, if a higher bond return is induced by a tightening of monetary policy, the capital return and thereby capital investment increase as well. However, this assumption of Diamond-type growth models neglects that firms finance (part of) their capital investment by equity and that the equity return exceeds the return on government bonds. If there is a positive spread between the equity and the bond return, a higher bond return need not increase the capital return, but may decrease the risk premium, induce investors to buy less equity, and thereby induce firms to accumulate less capital. Hence, the traditional Mundell-Tobin effect reappears.

This paper departs from the model of Schreft and Smith in two important ways. First, firms finance capital investments by equity instead of bonds, and the equity return exceeds the bond return since there are stochastic productivity shocks and since consumers are risk averse. Second, because of an Arrow-Romer spillover of capital investment on labor productivity, the aggregate technology exhibits increasing returns to scale, which gives rise to endogenous growth. This enables us to study the growth effects of monetary policy.

Specifically, consumers transfer the labor income of their first lifetime period to the second period by means of three assets: money, government bonds, and equity. Because of a liquidity constraint, consumers hold money even if it is returndominated by bonds and equity. ${ }^{3}$ Since consumers are risk averse and since the equity return is uncertain, both the equity and the bond demand can be positive when there is a positive (expected) equity premium. Firms finance capital investments only by issuing equity. The government consumes a fixed share of output and finances its deficit by bonds and by seignorage, whereas the monetary authority controls the money supply by conducting open-market operations. Hence, the monetary authority determines the seignorage revenue of the government and can apply different types of monetary strategies. We consider four monetary policy strategies: a constant money growth rule, a stabilization of the ratio of money to bonds, an inflation-targeting rule, and an interest-rate-targeting rule.

As with the model of Schreft and Smith, our model may well have multiple steady states, ${ }^{4}$ depending on the parameter specifications and on the monetary strategy. Only one of these steady states turns out to be stable and we find that money affects growth positively in the stable steady state and for any type of monetary strategy. Only under interest-rate targeting is the growth effect ambiguous and dependent on the size of the risk premium. If the risk premium is too low, an increase in 
the nominal interest target is accompanied by a larger increase in inflation, which leads to a lower real interest rate and thus to higher growth.

A loose monetary policy raises the seignorage revenue, which allows the government to issue fewer bonds and which thereby reduces the real bond return. Since the expected capital return is constant in our simple $A \mathrm{~K}$-type growth model, this must raise the equity premium and will induce consumers to shift more savings to capital, which leads to a higher growth rate. By the same mechanism, an increase of fiscal expenditures unambiguously reduces the growth rate in any stable steady state, which is in accordance with the findings of Barro (1990), since government services do not affect production or utility in our model. Moreover, we show that the mechanism does not hinge on the AK model, but operates also if growth is generated by human capital formation.

In our model the Fisher hypothesis does not hold because nominal interest rates and inflation do not move one-for-one, not even in the long run; the real bond return falls when monetary policy is relaxed. However, this feature of our model does not stand in contrast to econometric results on the Fisher hypothesis. ${ }^{5}$ More puzzling is our result that growth increases even when money growth rates are very high, which seems to be at odds with the empirical observation that inflation and growth are negatively correlated at high inflation rates. However, this evidence appears to be valid only when very high inflation observations are included in the regressions. ${ }^{6}$ Moreover, the impact of inflation on growth in our model turns out to be negligible at high inflation rates. The result that this relation does not become negative at high inflation rates may be due to our assumption that money and bonds are very bad substitutes from the liquidity perspective of consumers. If consumers had liquidity preferences for both money and bonds (as in Easterly et al., 1995), higher inflation rates would eventually lead consumers to hold more bonds and less equity.

Our argument provides an alternative to related work of van der Ploeg and Alogoskoufis (1994), who consider the impact of monetary policy in an overlapping generations model in the spirit of Weil (1991) and with endogenous growth due to an Arrow-Romer externality. They find that higher money growth rates affect growth positively since currently living generations do not benefit from tax cuts in the future, and therefore consume less and invest more, which increases the long-run real growth rate. In our model, however, such effects of intertemporal taxation are absent, and growth is raised by the monetary policy's impact on asset prices and the equity premium.

Our model also relates to Hahn and Solow (1995, Ch. 2) who consider a Diamond-type growth model in which consumers hold money because of a cashin-advance constraint. Unlike Schreft and Smith, Hahn and Solow not only focus on steady states in which money is return-dominated by bonds and in which the cash-in-advance constraint on consumers is binding (consumers are liquidity constrained), but they also analyze steady states in which the rates of return on money and bonds are equal (the nominal interest rate is zero) and in which consumers are portfolio indifferent. In this paper, we also consider such portfolio-indifference 
steady states, and we specify the fiscal and monetary policy rules implementing such Friedman rule equilibria.

The remainder of the paper is organized as follows: Section 2 describes the economic agents and derives the equilibrium equations. Section 3 examines the equilibrium growth paths of the model and discusses their existence, multiplicity, and comparative statics under a policy regime of constant money growth. Section 4 extends our main results to three alternative monetary policy rules, and Section 5 concludes. The appendix contains our model extension to human capital formation and proofs that are not included in the text.

\section{MODEL}

Consider an overlapping generations economy in which there are three types of agents: consumers, firms, and a government. They trade a composite consumption good and labor as well as three types of financial assets: money, bonds, and equity. The government issues fiat money and bonds, while firms finance their capital investments by issuing equity. Since the capital return is uncertain due to stochastic productivity shocks, risk-averse consumers require a positive equity premium. Furthermore, because of a liquidity constraint, money is held even when it is return-dominated by bonds. The agents are described in detail in the subsections that follow.

\subsection{Consumers}

The representative consumer is endowed with one unit of labor in his first period, which is supplied inelastically, and he consumes in his second period of life only. He aims to transfer his real labor income $w_{t}$ to the second period by holding money $\left(m_{t}\right)$, bonds $\left(b_{t}\right)$, or equity $\left(e_{t}\right)$. The corresponding real gross rates of return are $R_{t}^{M}=p_{t} / p_{t+1}, R_{t}^{B}$, and $R_{t}^{E}$, respectively. The consumer faces a liquidity constraint stating that a certain fraction of savings (=labor income) is held in the form of money, $m_{t} \geq \lambda w_{t}$, where $\lambda \in[0,1) .{ }^{7}$ Whereas $R_{t}^{M}$ and $R_{t}^{B}$ are foreseen with certainty, the equity return is uncertain and the consumer expects that $R_{t}^{E}$ will be normally distributed with density function $g\left(\cdot ; \bar{R}_{t}^{E}, \sigma^{2}\right)$, where $\bar{R}_{t}^{E}$ is the mean and $\sigma^{2}$ the variance, both of which are determined below. Moreover, the consumer is risk averse and his von Neumann-Morgenstern utility function is assumed to be $u_{t}\left(c_{t+1}\right)=-e^{-\rho_{t} c_{t+1}}$, where $\rho_{t}=\rho / w_{t}$ and $\rho>0$ is given. This means that the consumer's absolute risk aversion, $\rho_{t}$, decreases as his income increases and will imply that, on a balanced-growth path, he has constant relative risk aversion. The consumer's decision problem is

$$
\begin{gathered}
\max _{c_{t+1}, m_{t}, b_{t}, e_{t}} E u_{t}\left(c_{t+1}\right) \\
\text { s.t. } c_{t+1} \leq R_{t}^{M} m_{t}+R_{t}^{B} b_{t}+R_{t}^{E} e_{t}, \quad m_{t}+b_{t}+e_{t} \leq w_{t}, \\
m_{t} \geq \lambda w_{t}, \quad e_{t} \geq 0 .
\end{gathered}
$$


Notice that a necessary condition for a solution to this problem is that $R_{t}^{B} \geq R_{t}^{M}$, since we have not imposed a lower bound on bondholdings. If $R_{t}^{B}<R_{t}^{M}$, then the consumer could issue arbitrarily many bonds and hold cash in order to guarantee an arbitrarily high consumption level. When $R_{t}^{B}>R_{t}^{M}$, the liquidity constraint must be binding; hence we have

$$
R_{t}^{B} \geq R_{t}^{M}, \quad m_{t} \geq \lambda w_{t}, \quad\left(R_{t}^{B}-R_{t}^{M}\right)\left(m_{t}-\lambda w_{t}\right)=0 .
$$

The following lemma shows that the equity demand is an increasing function of income and the expected equity premium.

LEMMA 1. The consumer's equity demand is

$$
e_{t}^{d}=\max \left\{\frac{\bar{R}_{t}^{E}-R_{t}^{B}}{\rho \sigma^{2}} w_{t}, 0\right\} .
$$

An alternative formulation of Lemma 1 is

$$
\bar{R}_{t}^{E}=R_{t}^{B}+\frac{\rho \sigma^{2}}{w_{t}} e_{t}^{d}
$$

whenever $e_{t}^{d}>0$. This reflects the equity premium required because of uncertainty and risk aversion of consumers.

\subsection{Firms}

We assume that there is a continuum of risk-neutral firms that are distributed among $i=1, \ldots, n$ sectors, each comprising a mass 1 of firms. Firms in sector $i$ produce output $Y_{t i}$ from labor input $L_{t i}$ and capital input $K_{t i}$ using the production technology $Y_{t i}=\Phi_{t i} F\left(K_{t i}, A_{t} L_{t i}\right)$. A total factor productivity shock to sector $i$, $\Phi_{t i}$, is realized only after capital is installed and workers are hired, and all $\Phi_{t i}$ are (across time and sectors) independently and identically distributed with mean 1 and (finite) variance $\sigma_{\Phi}^{2} . F$ exhibits constant returns to scale and $A_{t}$ measures labor productivity at time $t$. Firms have to install capital a period in advance, which is financed by issuing equity. Thus, equity supply in period $t-1$ is $e_{t-1, i}=K_{t i}$. Since firms finance capital input by issuing equity instead of bonds, firms maximize profit with respect to labor while capital demand is determined consistently with capital supply of the investors and with the rationality of their expectations [see Hahn and Solow (1995, Ch. 4)].

Given $K_{t i}$ at the beginning of period $t$, firm $i$ 's expected profit maximization problem is

$$
\max _{L_{t i}} E\left[\Phi_{t i} F\left(K_{t i}, A_{t} L_{t i}\right)-w_{t} L_{t i}\right]
$$

which leads to

$$
w_{t}=A_{t}\left[f\left(k_{t i}\right)-k_{t i} f^{\prime}\left(k_{t i}\right)\right],
$$


where $k_{t i}=K_{t i} /\left(A_{t} L_{t i}\right)$ and $f\left(k_{t i}\right)=F\left(k_{t i}, 1\right)$. To endogenize $A_{t}$, we assume a positive spillover from aggregate investment on labor productivity, as suggested by Arrow (1962) and Romer (1986). To obtain a balanced-growth path, we use a linear relationship of the form

$$
A_{t}=\frac{1}{a} \bar{K}_{t}
$$

where $\bar{K}_{t}$ is the aggregate capital stock. ${ }^{8}$ Since there are $n$ sectors, we have in a symmetric equilibrium $K_{t i}=: K_{t}$ and $\bar{K}_{t}=n K_{t}$, while labor market clearing then implies $L_{t i}=: L_{t}=1 / n$, for all $i$. This, together with (5), yields $k_{t i}=a$, and substituted in (4), it implies

$$
w_{t}=\alpha \bar{K}_{t}=\alpha n e_{t-1, i} \quad \text { where } \quad \alpha=\frac{f(a)}{a}-f^{\prime}(a) .
$$

This in turn implies that the equity return is

$$
R_{t-1, i}^{E}=\frac{\Phi_{t i} F\left(K_{t}, A_{t} L_{t}\right)-w_{t} L_{t}}{K_{t}}=\Phi_{t i} \frac{f(a)}{a}-\alpha .
$$

Since the $\Phi_{t i}$ are i.i.d., so are the $R_{t-1, i}^{E}$, with expected value and variance

$$
E\left(R_{t-1, i}^{E}\right)=\frac{f(a)}{a}-\alpha=f^{\prime}(a) \quad \text { and } \quad \sigma_{R}^{2}=\sigma_{\Phi}^{2}\left[\frac{f(a)}{a}\right]^{2}
$$

Thus, the expected equity return is constant over time and equals the marginal product of capital at the balanced-growth level of the capital intensity. This result is due to the constant-returns assumption and it implies that if there was no uncertainty and if firms could issue bonds instead of equity, then firms would choose the same level of capital input at the interest rate $R_{t}^{B}=f^{\prime}(a)$. Therefore, bonds and equity would then also be equivalent from the perspective of firms.

We are now in a position to rationalize the expectations of consumers on the equity return. To reduce risk as much as possible, the consumer invests an equal share in each sector; that is,

$$
e_{t-1, i}=K_{t}=e_{t-1} / n
$$

Then, the rate of return of the consumer's equity portfolio is the random variable $R_{t-1}^{E}=(1 / n) \sum_{i=1}^{n} R_{t-1, i}^{E}$, with expected value $\bar{R}_{t-1}^{E}=f^{\prime}(a)$ and variance $\sigma^{2}=\sigma_{R}^{2} / n$. According to the central limit theorems of probability theory, for $n$ tending to infinity $R_{t-1}^{E}$ converges (in probability) to the degenerate random variable concentrated in $f^{\prime}(a)$ but, for $n$ sufficiently large but finite, its distribution is also well approximated by the normal distribution with expected value $f^{\prime}(a)$ and variance $\sigma_{R}^{2} / n .^{9}$ This gives support to the assumption that the consumer expects $R_{t-1}^{E}$ to be normally distributed with mean $f^{\prime}(a)$ and variance $\sigma_{R}^{2} / n$. 


\subsection{Government}

The government spends an amount $g_{t}$ of the composite consumption good and finances its deficit by issuing bonds and money. We assume that the government's expenditures are a constant share of expected output $E Y_{t}=[f(a) / a] \bar{K}_{t}$; that is, $g_{t}=q[f(a) / a] e_{t-1}$ where $q \in[0,1)$. Since there are no taxes, we interpret $g_{t}$ as the fiscal deficit and $q$ as the deficit share in GDP. The government satisfies its budget constraint

$$
R_{t-1}^{B} b_{t-1}+q \frac{f(a)}{a} e_{t-1}=b_{t}+m_{t}-R_{t-1}^{M} m_{t-1} .
$$

The left-hand side denotes real government expenditures on consumption and interest payments, and the right-hand side contains the newly issued bonds and a seignorage term.

\subsection{Equilibrium}

By Walras's law, equilibrium on the labor, money, bond, and equity markets implies that the goods market also is in equilibrium; that is, $Y_{t}=c_{t}+g_{t}+e_{t}$. Substituting (6) and (8) into the consumer's budget constraint yields

$$
m_{t}+e_{t}+b_{t}=\alpha e_{t-1} .
$$

Moreover, inserting (6) and (7) into (3) implies that

$$
R_{t}^{B}=f^{\prime}(a)-\frac{\rho \sigma^{2}}{\alpha} \frac{e_{t}}{e_{t-1}} .
$$

Inserting (6) into (2) yields

$$
R_{t}^{B} \geq R_{t}^{M}, \quad m_{t} \geq \lambda \alpha e_{t-1}, \quad\left(R_{t}^{B}-R_{t}^{M}\right)\left(m_{t}-\lambda \alpha e_{t-1}\right)=0 .
$$

Equations (9), (10), (11), and (12) are dynamical equations with endogenous variables $m_{t}, e_{t}, b_{t}, R_{t}^{B}$, and $R_{t}^{M}$ that permit us to study the evolution of the system, provided the number of state variables is reduced to four. This is achieved by specifications of monetary policy rules that we study in the sequel. We start out in the Section 3 by analyzing in detail a policy of constant money growth, before we explore in Section 4 how our results extend to alternative monetary policy rules.

\section{EFFECTS OF MONETARY AND FISCAL POLICY}

We consider in this section a policy of constant monetary growth and we analyze for which specifications of monetary and fiscal policy balanced-growth paths exist and how they are affected by changes in policy. Adopting a constant money growth rule means $M_{t}=\mu M_{t-1}$ for all $t$, with $\mu \geq 1$, where $M_{t}$ is nominal money. Recalling 
that $R_{t}^{M}=p_{t} / p_{t+1}$, this can equivalently be written

$$
m_{t}=\mu R_{t-1}^{M} m_{t-1}
$$

We express the equilibrium equations in terms of the following variables: $x_{t}:=b_{t} /\left(\alpha e_{t-1}\right)$ and $v_{t}:=m_{t} /\left(\alpha e_{t-1}\right)$ are the shares of bonds and money in savings, and $\gamma_{t}:=e_{t} / e_{t-1}$ is the growth rate. Then, the budget constraints of the government and of consumers, (9) and (10), are rewritten as

$$
\left[f^{\prime}(a)-\frac{\rho \sigma^{2}}{\alpha} \gamma_{t-1}\right] \frac{\alpha x_{t-1}}{\gamma_{t-1}}+q \frac{f(a)}{a}=\alpha x_{t}+\left(1-\frac{1}{\mu}\right) \alpha v_{t}
$$

and

$$
\frac{\gamma_{t}}{\alpha}+x_{t}+v_{t}=1
$$

The economy can be in two different states: (i) consumers are liquidity constrained (LC) at a positive nominal interest rate, which means that

$$
\begin{gathered}
v_{t}=\lambda \\
R_{t}^{B}=f^{\prime}(a)-\frac{\rho \sigma^{2}}{\alpha} \gamma_{t}>\frac{\gamma_{t}}{\mu}=R_{t}^{M}
\end{gathered}
$$

or (ii) the nominal interest rate is zero and consumers are portfolio indifferent (PI) between holding money and holding bonds - that is,

$$
\begin{gathered}
v_{t} \geq \lambda \\
R_{t}^{B}=f^{\prime}(a)-\frac{\rho \sigma^{2}}{\alpha} \gamma_{t}=\frac{v_{t+1}}{v_{t}} \frac{\gamma_{t}}{\mu}=R_{t}^{M} .
\end{gathered}
$$

Clearly, a portfolio-indifference equilibrium with zero nominal interest rate will be implemented only for a specific rate of money growth.

Consider first a liquidity-constrained equilibrium. Then $v_{t}=\lambda$ allows us to rewrite (14) and (15) as

$$
\left[f^{\prime}(a)-\frac{\rho \sigma^{2}}{\alpha} \gamma_{t-1}\right] \frac{\alpha x_{t-1}}{\gamma_{t-1}}+q \frac{f(a)}{a}=\alpha x_{t}+\left(1-\frac{1}{\mu}\right) \lambda \alpha
$$

and

$$
\gamma_{t}=\alpha\left(1-\lambda-x_{t}\right)
$$

respectively. Substituting the latter into the former, we obtain a one-dimensional dynamic equation in $x_{t}$ :

$$
\begin{aligned}
x_{t} & =\psi\left(x_{t-1}\right) \\
& =\frac{1}{\alpha}\left[f^{\prime}(a) \frac{x_{t-1}}{1-\lambda-x_{t-1}}-\rho \sigma^{2} x_{t-1}+q \frac{f(a)}{a}-\left(1-\frac{1}{\mu}\right) \lambda \alpha\right] .
\end{aligned}
$$




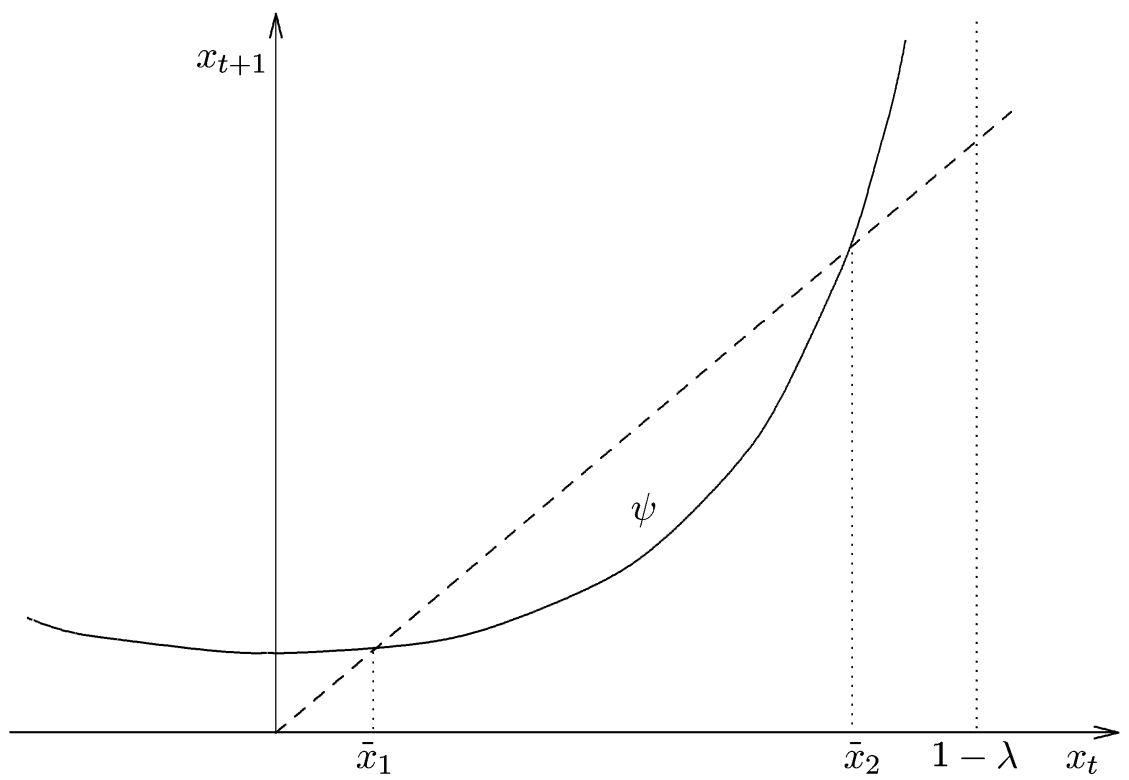

Figure 1. Steady states with liquidity-constrained consumers.

The graph of the function $\psi$ is illustrated in Figure 1 . Note that $e_{t} \geq 0$ requires that $x_{t} \leq 1-\lambda$. Figure 1 also shows two potential LC steady states: $\bar{x}_{1}<\bar{x}_{2}$. Because of (18), the associated growth rates are $\bar{\gamma}_{1}>\bar{\gamma}_{2}$. The steady state with the higher growth rate (with the lower bond share) is asymptotically stable and the other steady state is unstable. ${ }^{10}$ It is important to see that there is no steady state if the fiscal deficit is too large relative to the rate of money growth. Indeed, a larger (primary) fiscal deficit $q$ shifts $\psi$ upward so that both steady states may fail to exist. The maximum fiscal deficit compatible with a steady-state equilibrium can be derived as follows.

LEMMA 2. Necessary for the existence of two liquidity-constrained steady states is that the policy parameters $q$ and $\mu$ satisfy $q<q^{L C}(\mu)$, where

$$
\begin{aligned}
& q^{L C}(\mu):=\frac{a}{f(a)}\left\{(1-\lambda)\left(\alpha+\rho \sigma^{2}\right)+\left(1-\frac{1}{\mu}\right) \lambda \alpha+f^{\prime}(a)\right. \\
& \left.-2\left[f^{\prime}(a)(1-\lambda)\left(\alpha+\rho \sigma^{2}\right)\right]^{1 / 2}\right\}
\end{aligned}
$$

It is immediate that $q^{L C}$ is increasing in $\mu$ since higher seignorage allows for a higher deficit. We will need in the following the assumption:

Assumption 1.

$$
(1-\lambda)\left(\alpha+\rho \sigma^{2}\right)>f^{\prime}(a)
$$


which is plausibly satisfied whenever $\lambda$ is not too large, since the labor share $\alpha a / f(a)$ should exceed the capital share $f^{\prime}(a) a / f(a)$.

Under Assumption 1, the maximal fiscal deficit compatible with an LC steady state is increasing in uncertainty and/or risk aversion as measured by $\rho \sigma^{2}$. This is a plausible effect since higher uncertainty/risk aversion reduces the willingness of consumers to invest in equities and increases the willingness to hold bonds, leaving the government more scope for spending. It remains to check whether consumers are in fact liquidity constrained at the steady state, that is, whether the condition $R_{t}^{B}>R_{t}^{M}$ holds. From (16), this condition is satisfied at a steady state if

$$
f^{\prime}(a)-\frac{\rho \sigma^{2}}{\alpha} \bar{\gamma}>\frac{\bar{\gamma}}{\mu} .
$$

Obviously, this condition is stronger for the stable steady state with the higher growth rate and the lower bond share, so that it can be satisfied either for both steady states, only for the unstable one, or for none of them.

To examine this condition, it is useful to consider PI steady states in which the liquidity constraint is slack and in which (21) is satisfied with equality. From (17), the growth rate in a PI steady state is

$$
\bar{\gamma}=f^{\prime}(a)\left(\frac{1}{\mu}+\frac{\rho \sigma^{2}}{\alpha}\right)^{-1} .
$$

On the other hand, (14) reveals that the bond share $\bar{x}$ is indeterminate (since consumers are indifferent between holding money or holding bonds), whereas the growth rate satisfies, from (14) and (15),

$$
q \frac{f(a)}{a}=\left(1-\frac{1}{\mu}\right)(\alpha-\bar{\gamma}) .
$$

Equations (22) and (23) generally define the rate of money growth implementing the Friedman rule of a zero nominal interest rate. Solving these two equations yields Lemma 3.

LEMMA 3. A portfolio-constrained steady state exists if and only if the policy parameters $q$ and $\mu$ satisfy $q=q^{P I}(\mu)$, where

$$
q^{P I}(\mu):=\frac{a}{f(a)}\left(1-\frac{1}{\mu}\right)\left[\alpha-\frac{f^{\prime}(a)}{\frac{1}{\mu}+\frac{\rho \sigma^{2}}{\alpha}}\right] .
$$

The function $q^{P I}$ has a zero at $\mu=1$ and another zero at $\mu=\tilde{\mu}>1$ (under Assumption 1) and $q^{P I}(\mu)$ is positive in between. The intuition for this hump-shaped behavior is as follows: For low money growth rates ( $\mu$ is close to 1$)$, higher money growth leads to a higher seignorage revenue, so that the government may spend more without violating the Friedman rule. When money growth becomes higher, however, a zero nominal interest rate requires that the economy grow very fast so that the government needs to save in order to sustain the high 


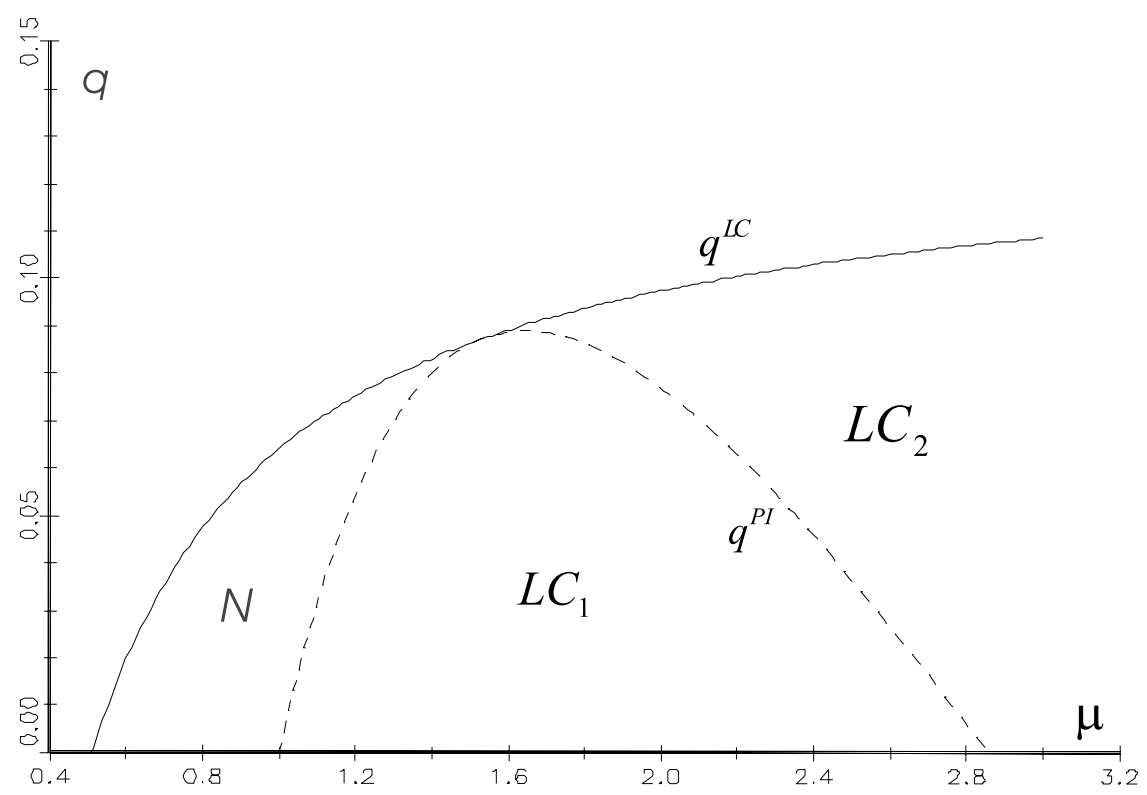

Figure 2. Monetary and fiscal policy regimes.

growth rates (households borrow to buy equities). This, in turn, lowers the scope for the fiscal deficit until it becomes zero at the money growth rate $\tilde{\mu}$.

It can be shown that $q^{P I}$ always stays below $q^{L C}$, and that both functions are tangential to each other, as illustrated in Figure 2, provided that Assumption 1 is satisfied. ${ }^{11}$ For fiscal and monetary policy parameters $q$ and $\mu$ on the dashed curve $q^{P I}$, a portfolio-indifference steady state exists. For which policies does there exist a liquidity-constrained steady state? Consider the PI steady state at $q=0, \mu=1$. With these policy parameters, (19) shows that the two candidate LC steady states are $\bar{x}_{1}=0$ and $\bar{x}_{2}>0$ with growth rates $\bar{\gamma}_{1}=\alpha(1-\lambda)$ and $\bar{\gamma}_{2}=\bar{\gamma}<\bar{\gamma}_{1}$, where $\bar{\gamma}$ is the growth rate in the PI steady state as defined in (22). Hence, only the unstable LC steady state satisfies condition (21), and the same is true when $\mu$ is slightly increased. On the other hand, when $q$ is increased from $q=0, \mu=1$, the growth rate in the unstable LC steady state increases, and therefore (21) must be violated at both candidate steady states. Therefore, no steady state exists in the policy regime $N$ in Figure 2 below $q^{L C}$ and to the left of $q^{P I}$. The region $L C_{1}$ shows the policy regime for which only the unstable steady state with the lower growth rate satisfies condition (21), whereas $L C_{2}$ shows the policy regime where both $L C$ steady states satisfy (21). Indeed, it can easily be checked that the PI steady state at $q=0$ and $\mu=$ $\tilde{\mu}$ falls together with the stable LC steady state. Hence, the part of $q^{P I}$ that separates $L C_{1}$ and $L C_{2}$ indicates that the nominal interest rate is zero at the high-growth (stable) LC steady state, whereas the part of $q^{P I}$ separating $N$ from $L C_{1}$ shows where the nominal interest rate is zero at the low-growth (unstable) LC steady state. 
PROPOSITION 1. Under constant money growth, there exists a stable steadystate equilibrium in which consumers are liquidity constrained, provided that the rate of money growth is sufficiently high and the fiscal deficit is sufficiently low relative to the rate of money growth (policy regime $L C_{2}$ ). If a stable steady state exists, the growth rate is higher if money growth is faster or if the fiscal share is lower. If the fiscal deficit is too high or if the rate of money growth is too low, there exists either no steady-state equilibrium (policy regime $N$ ) or a steady-state equilibrium that is unstable (policy regime $L C_{1}$ ).

In the regime $L C_{1}$, there exists only one steady state, which is unstable. The global dynamics in this case are difficult to analyze, but it is possible that there are cyclical equilibrium solutions fluctuating between liquidity-constrained and portfolio-indifference states. In the policy regime $L C_{2}$, on the other hand, there exists a unique stable steady state. ${ }^{12}$ In this regime, higher money growth or a lower fiscal deficit promotes growth.

\section{ALTERNATIVE MONETARY POLICY RULES}

We deviate in this section from the assumption of a constant money growth rate to three alternative monetary policy regimes. We investigate the robustness of our main result that expansive monetary policy promotes growth in the stable steady state. This result can be confirmed when the monetary authority fixes the ratio of money supply to debt and when it targets the inflation rate. Under interest-rate targeting, the results are ambivalent and depend critically on the equity premium.

\subsection{Interest-Rate Targeting}

In this case the central bank intends to fix the nominal interest factor $I_{t}$ at a value $I>1$ for all $t$. Since $I=R_{t}^{B} / R_{t}^{M}$, consumers are liquidity constrained, $m_{t}=\lambda \alpha e_{t-1}$. Equation (9) now becomes

$$
\begin{aligned}
& {\left[f^{\prime}(a)-\frac{\rho \sigma^{2}}{\alpha} \gamma_{t-1}\right] b_{t-1}+q \frac{f(a)}{a} e_{t-1}} \\
& \quad=b_{t}+\lambda \alpha e_{t-1}-\frac{1}{I}\left[f^{\prime}(a)-\frac{\rho \sigma^{2}}{\alpha} \gamma_{t-1}\right] \lambda \alpha e_{t-2} .
\end{aligned}
$$

Again, setting $x_{t}=b_{t} /\left(\alpha e_{t-1}\right)$, dividing by $e_{t-1}$, and using (18) yields

$$
\begin{aligned}
& {\left[f^{\prime}(a)-\rho \sigma^{2}\left(1-\lambda-x_{t-1}\right)\right] \frac{x_{t-1}}{1-\lambda-x_{t-1}}+q \frac{f(a)}{a}} \\
& \quad=\alpha x_{t}+\lambda \alpha-\frac{1}{I}\left[\frac{f^{\prime}(a) \lambda}{1-\lambda-x_{t-1}}-\rho \sigma^{2} \lambda\right] .
\end{aligned}
$$


Solving for $x_{t}$, we obtain

$$
x_{t}=\frac{1}{\alpha}\left[f^{\prime}(a) \frac{x_{t-1}+\lambda / I}{1-\lambda-x_{t-1}}-\rho \sigma^{2} x_{t-1}+q \frac{f(a)}{a}-\lambda\left(\alpha+\frac{\rho \sigma^{2}}{I}\right)\right] .
$$

The graph of this function is qualitatively the same as the one shown in Figure 1. Higher uncertainty or risk aversion and a lower level of government spending shift the curve downward, decreasing $\bar{x}_{1}$ and increasing $\bar{\gamma}_{1}$.

Regarding the effect of a change in the nominal interest rate, we have

$$
\frac{\partial x_{t}}{\partial I}=\frac{\lambda}{\alpha}\left[\rho \sigma^{2}-\frac{f^{\prime}(a)}{1-\lambda-x_{t-1}}\right] \frac{1}{I^{2}} .
$$

For small uncertainty/risk aversion, this derivative is negative, implying that an increase in $I$ decreases $\bar{x}_{1}$ and increases $\bar{\gamma}_{1}$, whereas for large $\rho \sigma^{2}$, the effect is reversed. If the uncertainty and risk aversion are low, the increase in the nominal interest rate is accompanied by a larger increase in the inflation rate, which lowers the real interest rate and raises capital investment. On the other hand, if uncertainty and risk aversion are large, the inflation rate increases less than the nominal interest rate, and so, the real interest rate increases as well, which affects growth negatively. We therefore have obtained the following result.

PROPOSITION 2. Under interest-rate targeting, there exist no or two steady states. The steady state with the higher growth rate is asymptotically stable. A decrease in the fiscal deficit increases the growth rate and the risk premium. The effect of the nominal interest target on growth is positive if uncertainty or risk aversion is small, whereas it is negative if uncertainty or risk aversion is large.

\subsection{Inflation Targeting}

Under inflation targeting the central bank aims to have $R_{t}^{M}=R^{M}$ for all $t$ and $R^{M}>0$ predetermined. Proceeding as in the preceding section, the case $R_{t}^{B}>R^{M}$ yields

$$
\begin{aligned}
& {\left[f^{\prime}(a)-\rho \sigma^{2}\left(1-\lambda-x_{t-1}\right)\right] \frac{x_{t-1}}{1-\lambda-x_{t-1}}+q \frac{f(a)}{a}} \\
& \quad=\alpha x_{t}+\lambda \alpha\left[1-\frac{R^{M}}{\alpha\left(1-\lambda-x_{t-1}\right)}\right]
\end{aligned}
$$

and therefore

$$
x_{t}=\frac{1}{\alpha}\left[\frac{f^{\prime}(a) x_{t-1}+\lambda R^{M}}{1-\lambda-x_{t-1}}-\rho \sigma^{2} x_{t-1}+q \frac{f(a)}{a}-\lambda \alpha\right] .
$$

The graph of this function is again as in Figure 1. Regarding the comparative statics properties of the steady states, they are analogous to the case of interest-rate targeting. The only difference is that now an increase in the inflation rate (a lower 
$R^{M}$ ) unambiguously lowers the real interest rate and increases the growth rate. When is it true that in a steady state $R^{B}>R^{M}$ ? From (11), a necessary condition is $f^{\prime}(a)>R^{M}$. This means that too low an inflation rate is unsustainable on a steadystate growth path with liquidity-constrained consumers. Portfolio indifference, on the other hand, requires, from (11), that the growth rate be constant with value

$$
\gamma=\left[f^{\prime}(a)-R^{M}\right] \frac{\alpha}{\rho \sigma^{2}},
$$

which cannot be fulfilled when $\rho \sigma^{2}=0$ (unless $R^{M}$ happens to be equal to $f^{\prime}(a)$ ). However, also when $\rho \sigma^{2}$ is positive, steady states with $R^{B}=R^{M}$ exist only if $R^{M}$ assumes a specific value in correspondence to the value of the fiscal share $q$. To show this, we use again the variables $x_{t}$ and $v_{t}$ to denote the shares of bonds and money in savings as defined in Section 3. Then (15) implies that $x_{t}+v_{t}=1-\gamma_{t} / \alpha$, whereas (9) yields

$$
q \frac{f(a)}{a}=\alpha-\gamma-R^{M}\left(\frac{\alpha}{\gamma}-1\right) .
$$

Inserting (24) into this equation reveals a hump-shaped behavior between the fiscal deficit and the monetary policy parameter $q=q^{P I}\left(R^{M}\right)$, similar to the one in Lemma 3. Qualitatively our results are thus similar to Proposition 1.

PROPOSITION 3. Under inflation targeting, there exists a stable steady-state equilibrium in which consumers are liquidity constrained provided that the inflation target is sufficiently high and the fiscal deficit is sufficiently low. If a stable steady state exists, the growth rate increases if the inflation target is higher or if the fiscal deficit is lower. If the fiscal deficit is too high or if the rate of money growth is too low, there exists either no steady-state equilibrium or a steady-state equilibrium that is unstable.

\subsection{Fixed Money-Bond Ratio}

We assume here along the lines of Schreft and Smith (1998) that the monetary authority stabilizes the money supply relative to the level of public debt in the economy. That is, it fixes the ratio of bonds to money, $b_{t} / m_{t}=\kappa$ for all $t$. Higher levels of $\kappa$ represent an increase in the bond-money ratio and correspond to a tighter monetary regime. Starting with the case $R_{t}^{B}>R_{t}^{M}, m_{t}=\lambda \alpha e_{t-1}$, and (10) yield

$$
e_{t}=[1-(1+\kappa) \lambda] \alpha e_{t-1}
$$

Therefore,

$$
\gamma_{t}=\alpha[1-(1+\kappa) \lambda]=\bar{\gamma},
$$

which means that the growth rate is constant and independent of $q$ and $\rho \sigma^{2}$. Since the central bank fixes the mix of government liabilities (bonds and outside money) 
over time, fiscal policy has no effect on growth. Furthermore, it follows that

$$
x_{t}=\kappa \lambda=\bar{x}
$$

and thus also $x_{t}$ is constant and independent of $q$ and $\rho \sigma^{2}$. By (11), the steady-state bond return is

$$
R^{B}=f^{\prime}(a)-\frac{\rho \sigma^{2}}{\alpha} \bar{\gamma}
$$

These results imply that a tighter monetary policy (an increase in $\kappa$ ) increases bond supply and the bond return, reduces the equity premium, increases the ratio of bonds to capital, and decreases the growth rate. From (9), (11), and $m_{t}=\lambda \alpha e_{t-1}$,

$$
R_{t-1}^{M}=(1+\kappa) \gamma_{t-1}-\left[f^{\prime}(a)-\frac{\rho \sigma^{2}}{\alpha} \gamma_{t-1}\right] \kappa-\frac{q}{\lambda \alpha} \frac{f(a)}{a} \gamma_{t-1},
$$

which in equilibrium becomes

$$
R^{M}=\left[1+\kappa+\frac{\rho \sigma^{2}}{\alpha} \kappa-\frac{q}{\lambda \alpha} \frac{f(a)}{a}\right] \bar{\gamma}-f^{\prime}(a) \kappa .
$$

This enables us now to check the validity of the assumption that $R^{M}<R^{B}$. Using (25), (26), and (27), we can restate this condition as

$$
\left[(1+\kappa)\left(1+\frac{\rho \sigma^{2}}{\alpha}\right)-\frac{q}{\lambda \alpha} \frac{f(a)}{a}\right][1-(1+\kappa) \lambda] \alpha<(1+\kappa) f^{\prime}(a) .
$$

For given values of the other parameters, this condition can always be fulfilled when $\kappa$ and/or $q$ are big enough.

To complete the analysis we also consider the case of portfolio indifference: that is, $R_{t}^{M}=R_{t}^{B}$. From (10), we obtain

$$
(1+\kappa) m_{t}+e_{t}=\alpha e_{t-1},
$$

whereas (9) and (11) yield

$$
\left[f^{\prime}(a)-\frac{\rho \sigma^{2}}{\alpha} \frac{e_{t-1}}{e_{t-2}}\right](1+\kappa) m_{t-1}+q \frac{f(a)}{a} e_{t-1}=(1+\kappa) m_{t} .
$$

Using again $v_{t}=m_{t} /\left(\alpha e_{t-1}\right)$ for the money share in savings, these equations can be written as

$$
\gamma_{t}=\alpha\left[1-(1+\kappa) v_{t}\right]
$$

and

$$
\left[f^{\prime}(a)-\frac{\rho \sigma^{2}}{\alpha} \gamma_{t-1}\right] \frac{\alpha(1+\kappa) v_{t-1}}{\gamma_{t-1}}+q \frac{f(a)}{a}=\alpha(1+\kappa) v_{t} .
$$


Substituting $\chi_{t}:=(1+\kappa) v_{t}$ and inserting the first equation into the second yields

$$
\chi_{t}=q \frac{f(a)}{\alpha a}+\left[\frac{f^{\prime}(a)}{\alpha}-\frac{\rho \sigma^{2}}{\alpha}\left(1-\chi_{t-1}\right)\right] \frac{\chi_{t-1}}{1-\chi_{t-1}}=: \phi\left(\chi_{t-1}\right) .
$$

To explore the existence of steady states, let us start with the case $q=0$. Then, $\bar{\chi}=0$ is one steady state and, since $\phi(\chi) \rightarrow \infty$ as $\chi \rightarrow 1$, an additional positive (unstable) steady state exists, provided $\phi^{\prime}(0)<1$. However, this condition is satisfied under the plausible assumption that $f^{\prime}(a)<\alpha$ (i.e., the capital share is lower than the labor share). Then, as $q$ is slightly increased, $\phi(0)>0$, and a positive steady states $\bar{\chi}$ emerges, in addition to the other unstable steady state. The steadystate value $\bar{\chi}$ and thereby the steady state growth rate $\bar{\gamma}$ are independent of the monetary policy parameter $\kappa$. However, the steady state is only an equilibrium of our model if also the liquidity constraint $m_{t} \geq \lambda \alpha e_{t-1}$ is satisfied. This constraint means that

$$
\bar{\chi} \geq \lambda(1+\kappa)
$$

which is satisfied when $\lambda$ and/or $\kappa$ are small enough. That is, a not too restrictive liquidity constraint and a sufficiently loose monetary policy give rise to a steady state in which the nominal interest rate is zero and in which consumers are portfolio indifferent. In conclusion, we thus have Proposition 4.

PROPOSITION 4. Under a fixed bond-money ratio $b_{t} / m_{t}=\kappa$, there is, at most, one equilibrium in which consumers are liquidity constrained and which must be a steady state. In such an equilibrium, a tightening of the monetary regime (i.e., a higher $\kappa$ ) decreases the growth rate, whereas fiscal policy does not affect growth. If the monetary regime is sufficiently loose, steady states in which consumers are portfolio indifferent also exist, provided the fiscal deficit is not too large. In these steady states the growth rate is independent of $\kappa$.

\section{CONCLUSIONS}

We have considered an economy where consumers hold two outside assets (money and government bonds) and capital, and where the central bank can apply different monetary strategies to promote growth. Multiple steady states with positive nominal interest rates exist, whereas portfolio indifference steady states in which the nominal interest rate is zero exist only if monetary and fiscal policy parameters are suitably coordinated. This result extends the analysis of Hahn and Solow (1995, Ch. 2) who focus on portfolio-indifference steady states when fiscal deficit and money growth are zero and who argue that, in this scenario, portfolio-indifference steady states give rise to instability and endogenous fluctuations.

Even though there are multiple steady states in our model, only one of them is stable. For the case of constant money growth, we have completely characterized the set of fiscal and monetary policy parameters according to whether they are compatible with two steady states, one (unstable) steady state, or no steady state. 
An expansive monetary policy enhances growth in the stable steady state, and this result extends to all monetary strategies analyzed. It lowers the real interest rate, raises the risk premium and promotes capital accumulation. Monetary growth that is too low, on the other hand, is (at least in the case of constant money growth) incompatible with stable steady states, and we conjecture that it may give rise to fluctuations and other complex dynamics (as in Hahn \& Solow, 1995). This issue may be resolved in future research.

To keep our model analytically tractable, we have assumed that consumers consume only in old age and save all their labor income. A more general savings behavior would allow the study of the interaction between portfolio choice and savings, and this interaction may be relevant also for the policy conclusions. ${ }^{13}$ For another simplification - the assumption of an Arrow-Romer externality leading to endogenous growth-we have shown that it is not crucial to our central result. In fact, when endogenous growth is generated from human capital formation, it is still true that tight monetary policy is harmful for growth at the stable balanced-growth path.

\section{NOTES}

1. See, for instance, Sidrauski (1967), Brock (1974), and Stockman (1981). More recently, Jones and Manuelli (1995) have shown a negative correlation between inflation and growth in an endogenous growth model, and Azariadis and Smith (1996) have found a negative relationship between inflation and output at high inflation, which is reversed at low inflation. For surveys on money and growth, see Orphanides and Solow (1990) and von Thadden (1999).

2. In fact, most empirical studies report a negative correlation between inflation and growth, which is particularly strong at high inflation rates. However, Bullard and Keating (1995) and McCandless and Weber (1995) show that inflation (money growth, respectively) and growth are uncorrelated in large samples, whereas they are positively correlated in subsamples of low-inflation countries.

3. In Schreft and Smith's model, the use of money is motivated by random liquidity shocks, and liquidity is provided by banks. Our liquidity constraint is equivalent to the banks' liquidity constraint of Schreft and Smith (1997) if consumers are assumed to have logarithmic preferences.

4. We use the term steady state to denote a balanced-growth path.

5. Some literature clearly argues against long-run superneutrality of money. King and Watson (1992), using U.S. postwar data, conclude that "the data do not appear to be consistent with the hypothesis that, over the long run, money is superneutral or that nominal interest rates move one-forone with inflation." Weber (1994) obtains similar results for G-7 countries.

6. Bruno and Easterly (1998) find that there is no significant correlation between 5-year averages of growth and inflation, once discrete high-inflation (above 40\%) observations are excluded. Results for cross-sectional correlations of long-run averages are similar.

7. Our liquidity constraint is similar in spirit to a cash-in-advance constraint stating that a fraction of consumption expenditures must be financed with money. Since future consumption is stochastic in our model, we prefer to relate money holdings to savings rather than to consumption.

8. Although this simple "AK model" is a standard tool in the endogenous-growth literature, it requires implausibly high increasing returns at the aggregate level. We show in Appendix A.2 how our model and its main implications can be extended to human capital formation.

9. Under mild regularity assumptions, the distribution of the random variable $X_{n}:=\left[(1 / n) \sum_{i=1}^{n}\right.$ $\left.R_{t-1, i}^{E}-f^{\prime}(a)\right] / \sqrt{\sigma_{R}^{2} / n}$ converges (weakly) to the unit normal distribution $\mathcal{N}(0,1)$, and the distribution of $R_{t-1}^{E}=\sqrt{\sigma_{R}^{2} / n} \cdot X_{n}+f^{\prime}(a)$ is approximately $\mathcal{N}\left[f^{\prime}(a), \sigma_{R}^{2} / n\right]$. 
10. In our model, there is no indeterminacy since the initial bond share $x_{0}$ does not depend on expectations. This is a consequence of our assumption that neither savings nor the coefficient of the Clower constraint $\lambda$ is influenced by inflation expectations. Compare also with Schreft and Smith (1997, p. 175).

11. If Assumption 1 is satisfied with equality, the two functions are equal at $\mu=1$, and when Assumption 1 holds with reverse inequality, $q^{P I}$ stays strictly below $q^{L I}$ for all $\mu$. Figure 2 is based on the parameters $f(a) / a=1$ (output), $\alpha=2 / 3$ (labor share), $f^{\prime}(a)=1 / 3$ (capital share), $\lambda=0.1$, and $\rho \sigma^{2}=0.1$.

12. In a previous working-paper version, we showed that the steady state with the higher (lower) growth rate is not only stable (unstable) in the forward dynamics with rational expecatations, but also under adaptive learning. This gives further support to our claim that the high-growth steady state is the relevant one.

13. Although it is easy to include first-period consumption in the consumer's model and to obtain a nontrivial savings decision, the resulting dynamical system becomes cumbersome to deal with.

14. Without the Arrow-Romer externality $(\phi=1)$, this model generates a growth rate that only depends on the training technology, but not on fiscal and monetary policy. This is due to our simplifying assumption that households work only in one period.

\section{REFERENCES}

Arrow, K.J. (1962) The economic implications of learning by doing. Review of Economic Studies 29, $155-173$.

Azariadis, C. \& A. Drazen (1989) Threshold externalities in economic development. Quarterly Journal of Economics 105, 501-526.

Azariadis, C. \& B. Smith (1996) Private information, money, and growth: Indeterminacy, fluctuations, and the Mundell-Tobin effect. Journal of Economic Growth 1, 309-332.

Barro, R.J. (1990) Government spending in a simple model of endogenous growth. Journal of Political Economy 98 (P. 2), S103-S125.

Brock, W. (1974) Money and growth: The case of long run perfect foresight. International Economic Review 15, 750-761.

Bruno, M. \& W. Easterly (1998) Inflation crises and long-run growth. Journal of Monetary Economics 41, 3-26.

Bullard, J. \& J.W. Keating (1995) The long-run relationship between inflation and output in postwar economies. Journal of Monetary Economics 36, 477-496.

Easterly, W., P. Mauro, \& K. Schmidt-Hebbel (1995) Money demand and seignorage-maximizing inflation. Journal of Money, Credit and Banking 27, 583-603.

Hahn, F. \& R. Solow (1995) A Critical Essay on Modern Macroeconomic Theory. Oxford: Blackwell.

Jones, L.E. \& R.E. Manuelli (1995) Growth and the effects of inflation. Journal of Economic Dynamics and Control 19, 1405-1428.

King, R. \& M.W. Watson (1992) Testing Long-Run Neutrality. NBER working paper, 4156.

Lucas, R. (1988) On the mechanics of economic development. Journal of Monetary Economics 22, $3-42$.

McCandless, G.T. \& W.E. Weber (1995) Some monetary facts. Federal Reserve Bank of Minneapolis, Quarterly Review 19, 2-11.

Mundell, R. (1965) Growth, stability, and inflationary finance. Journal of Political Economy 73, 97-109.

Orphanides, A. \& R. Solow (1990) Money, inflation and growth. In M. Friedman \& F. Hahn (ed.), Handbook of Monetary Economics, vol. I. Amsterdam: North-Holland.

Romer, P.M. (1986) Increasing returns and long-run growth. Journal of Political Economy 94, 10021037. 
Schreft, S.L. \& B.D. Smith (1997) Money, banking, and capital formation. Journal of Economic Theory $73,157-182$.

Schreft, S.L. \& B.D. Smith (1998) The effects of open market operations in a model of intermediation and growth. Review of Economic Studies 65, 519-550.

Sidrauski, M. (1967) Rational choice and patterns of growth in a monetary economy. American Economic Review: Papers and Proceedings 51, 534-544.

Stockman, A. (1981) Anticipated inflation and the capital stock in a cash-in-advance economy. Journal of Monetary Economics 8, 387-393.

Tobin, J. (1965) Money and economic growth. Econometrica 33, 671-684.

van der Ploeg, F. \& G.S. Alogoskoufis (1994) Money and endogenous growth. Journal of Money, Credit, and Banking 26, 771-791.

von Thadden, L. (1999) Money, inflation, and capital formation. Lecture Notes in Economics and Mathematical Systems, Vol. 479. Berlin: Springer-Verlag.

Weber, A.A. (1994) Testing long-run neutrality: Empirical evidence for G7-countries, with special emphasis on Germany. Carnegie-Rochester Conference Series on Public Policy 41, 67-117.

Weil, P. (1991) Is money net wealth? International Economic Review 32, 37-53.

\section{APPENDIX}

\section{A.1. PROOFS}

Proof of Lemma 1. The consumer's problem is

$$
\max _{m_{t}, b_{t}, e_{t}} \int-e^{-\rho_{t}\left(R_{t}^{M} m_{t}+R_{t}^{B} b_{t}+r e_{t}\right)} g\left(r ; \bar{R}_{t}^{E}, \sigma^{2}\right) d r
$$

subject to the constraints in (1). The integral can be written

$$
-e^{-\rho_{t}\left(R_{t}^{M} m_{t}+R_{t}^{B} b_{t}\right)} \int e^{-\rho_{t} r e_{t}} g\left(r ; \bar{R}_{t}^{E}, \sigma^{2}\right) d r
$$

and, using the formula $\int e^{t x} g\left(x ; \nu, \sigma^{2}\right) d x=e^{t v+\left(t^{2} / 2\right) \sigma^{2}}$, it becomes

$$
-e^{-\rho_{t}\left[R_{t}^{M} m_{t}+R_{t}^{B} b_{t}+\bar{R}_{t}^{E} e_{t}-\left(\rho_{t} / 2\right) e_{t}^{2} \sigma^{2}\right]} .
$$

Substituting $b_{t}=w_{t}-m_{t}-e_{t}$, the problem is equivalent to

$$
\max _{m_{t} \geq \lambda w_{t}, e_{t} \geq 0}\left(R_{t}^{M}-R_{t}^{B}\right) m_{t}+\left(\bar{R}_{t}^{E}-R_{t}^{B}\right) e_{t}-\left(\rho_{t} / 2\right) e_{t}^{2} \sigma^{2} .
$$

The solution of this problem leads immediately to (2) and to the claimed equity demand.

Proof of Lemma 2. From equation (19), a steady-state share of bonds in income, $x=$ $\bar{x}$, has to satisfy

$$
f^{\prime}(a) \frac{x}{1-\lambda-x}-\rho \sigma^{2} x+q \frac{f(a)}{a}=\alpha x+\left(1-\frac{1}{\mu}\right) \lambda \alpha .
$$


The maximum deficit $q$ compatible with a steady state, $q^{L C}(\mu)$, is thus equal to the maximum value $Q\left(x_{m}\right)$ of the function

$$
Q(x)=\frac{a}{f(a)}\left[\left(\alpha+\rho \sigma^{2}\right) x+\left(1-\frac{1}{\mu}\right) \lambda \alpha-f^{\prime}(a) \frac{x}{1-\lambda-x}\right], \quad x<1-\lambda .
$$

Setting $Q^{\prime}(x)=0$ implies $(1-\lambda-x)^{2}=f^{\prime}(a)(1-\lambda) /\left(\alpha+\rho \sigma^{2}\right)$ and, since $x<1-\lambda$, $x_{m}=1-\lambda-\left[f^{\prime}(a)(1-\lambda) /\left(\alpha+\rho \sigma^{2}\right)\right]^{1 / 2}$. Inserting in $Q(x)$ yields $(20)$.

\section{A.2. HUMAN CAPITAL}

Our analysis so far has focused on a simple Arrow-Romer externality in which the spillover from aggregate capital on labor productivity supports long-run growth. Although this simple "AK model" is a standard tool in the endogenous growth literature, it requires too high a degree of increasing returns at the aggregate level to be compatible with the data. We therefore demonstrate in this appendix that a case for expansive monetary policy to promote growth can also be made in another version of this model in which human capital serves as the engine of growth. Human capital formation models can generate endogenous growth, provided that human capital per worker can increase over time without bounds (see Lucas, 1988). Households have access to a training technology (education) in which they can invest some of their labor endowment to increase their subsequent labor productivity and, as a consequence, their wage. To keep the model simple and to remain close to our prior analysis, we still assume that households live only two periods and work only in the first period of their life. Every worker decides at the beginning of the period how much of his labor endowment he devotes to training, and this training has an immediate impact on his labor productivity. To further simplify the analysis, we also assume that both the training technology and the production technology are Cobb-Douglas functions.

Every household $h$ that is young in period $t$ decides how much of its time $\tau_{t h}$ it invests in training to improve its quality of labor $A_{t h}$. All households have access to the common training technology

$$
A_{t h}=\tau_{t h}^{\zeta} A_{t-1}^{\phi} \bar{K}_{t}^{1-\phi},
$$

where $\varsigma>0$ and $\phi \in[0,1] . A_{t-1}$ is the common quality of labor of generation $t-1$ that is inherited by all households of generation $t$. Furthermore, there is again an externality from the aggregate capital stock in period $t$ on the quality of labor, but the degree may be considerably smaller than in the pure Arrow-Romer model before. ${ }^{14}$ What we need in order to generate a (linear) balanced-growth path is the assumption that the training technology and the production technology have constant returns to scale in the accumulable factors $A$ and $K$. Household $h$ anticipates that it will be paid the wage $w_{t h}=A_{t h}\left[f\left(k_{t}\right)-k_{t} f^{\prime}\left(k_{t}\right)\right]$ per unit time and chooses therefore $\tau_{t h}$ to maximize its first-period labor income $\left(1-\tau_{t h}\right) w_{t h}$. Since the training technology is the same for all households, all households invest the same time in training, and since we assume a Cobb-Douglas training technology, the solution does not depend on the aggregate state and thus is independent of time, $\tau_{t h}=\hat{\tau}$ for all $t$ and $h$. Therefore, $A_{t h}=A_{t}$ and (A.1) can be expressed as

$$
k_{t}=\hat{\tau}^{-\zeta} k_{t-1}^{\phi} \gamma_{t-1}^{\phi}
$$

where $k_{t}=\bar{K}_{t} /\left(A_{t} L_{t}\right)$ is the ratio of physical to human capital, and $\gamma_{t-1}=\bar{K}_{t} / \bar{K}_{t-1}$ is the growth rate. Hence, when $\phi>0, k_{t}$ is not a constant anymore but evolves according to 
the additional dynamic equation (A.2). To find a steady state (a balanced-growth path), we solve (A.2) for the steady-state level of $k$ :

$$
\bar{k}=\hat{\tau}^{-\frac{\zeta}{1-\phi}} \bar{\gamma}^{\frac{\phi}{1-\phi}} .
$$

The expected equity return, $f^{\prime}(k)$, the output-capital ratio, $f(k) / k$, and the labor income per unit of capital, $\alpha=f(k) / k-f^{\prime}(k)$, are now functions of the dynamic variable $k$. Assuming that the production function is Cobb-Douglas, $f(k)=k^{1-\beta}$, their steady-state values are

$$
f^{\prime}(\bar{k})=(1-\beta) \bar{k}^{-\beta}, \quad \frac{f(\bar{k})}{\bar{k}}=\bar{k}^{-\beta}, \quad \text { and } \quad \bar{\alpha}=\frac{f(\bar{k})}{\bar{k}}-f^{\prime}(\bar{k})=\beta \bar{k}^{-\beta} .
$$

From (18) and using (A.3) and (A.4), we can express the steady-state growth rate again as a function of the steady-state bond share:

$$
\bar{\gamma}=\hat{\tau}^{\frac{\beta_{\zeta}}{1-\phi(1-\beta)}}[\beta(1-\lambda-\bar{x})]^{\frac{1-\phi}{1-\phi(1-\beta)}} .
$$

The steady-state bond share $\bar{x}$ in the liquidity-constrained regime is again determined by a fixed-point $x=\psi(x)$ with $\psi$ as defined in (19). Using the new variables (A.4) and the equations (A.3) and (A.5), this identity becomes

$\bar{x}=\psi(\bar{x})=\frac{1-\beta}{\beta} \frac{\bar{x}}{1-\lambda-\bar{x}}-\frac{\rho \sigma^{2}}{\beta} \hat{\tau}^{-\frac{\beta \zeta}{1-\phi(1-\beta)}} \bar{x}[\beta(1-\lambda-\bar{x})]^{\frac{\beta \phi}{1-\phi(1-\beta)}}+\frac{q}{\beta}-\lambda\left(1-\frac{1}{\mu}\right)$.

It can be easily seen that the right-hand side of this equation falls together with the original function $\psi$ when there is no uncertainty. In this case, human capital formation operates in the same way as the AK model, so that there are two steady states (one stable, one unstable) whenever the fiscal deficit is not too high. This similarity of the two growth models is due to our assumption of Cobb-Douglas production and training functions. With more general production and training functions, the model may potentially generate multiple stable balanced-growth paths, as does the model of Azariadis and Drazen (1989). When there is uncertainty, however, the right-hand side of (A.6) changes its shape, but it still converges to infinity when $\bar{x} \rightarrow 1-\lambda$ or when $\bar{x} \rightarrow-\infty$, and it attains the same value at $\bar{x}=0$ as the original $\psi$. We also confirmed in various plots that there can be no more than two steady-states, and whenever there are two steady-states, the one with the lower bond share (the higher growth rate) must be stable. Since expansive monetary policy shifts $\psi$ downward, the growth rate in the stable steady state goes up. 